\title{
Social network members who engage in activities with older adults: do they bring more social benefits than other members?
}

\author{
SATO ASHIDA*, DANIEL K. SEWELL $\dagger$, ELLEN J. SCHAFER + , \\ AUDREY SCHROER* and JULIA FRIBERG*
}

\begin{abstract}
Active participation in social activities is important for the wellbeing of older adults. This study explored benefits of active social engagement by evaluating whether relationships that comprise active involvement (e.g. co-engagement in activities) bring more social benefits (i.e. social support, companionship, positive social influence) than other relationships that do not involve co-engagement. A total of 133 adults ages 6o years and older living in a rural Midwestern city in the United States of America were interviewed once and provided information on 1,740 social network members. Among 1,506 social relationships in which interactions occurred at least once a month, $5^{2}$ per cent involved engagement in social activities together and 35 per cent involved eating together regularly. Results of the generalised linear mixed model showed that relationships involving co-engagement were significantly more likely to also convey social support (i.e. emotional, instrumental, informational), companionship and social influence (encouragement for healthy behaviours) than relationships that do not involve co-engagement. Having more network members who provide companionship was associated with higher sense of environmental mastery, positive relations with others and satisfaction with social network. Interventions may focus on maintaining and developing such social relationships and ensuring the presence of social settings in which co-engagement can occur. Future research may explore whether increasing co-engagement leads to an enhanced sense of companionship and psychological wellbeing.
\end{abstract}

KEY WORDS-social relationships, community-based older adults, rural community.

* Department of Community \& Behavioral Health, The University of Iowa College of Public Health, The University of Iowa Aging Mind and Brain Initiative, Iowa City, Iowa, USA.

$\uparrow$ Department of Biostatistics, The University of Iowa College of Public Health, Iowa City, Iowa, USA.

+ Department of Community and Family Health, University of South Florida College of Public Health, Tampa, Florida, USA. 


\section{Introduction}

Social networks provide contexts within which older adults can be socially embedded and gain opportunities to be engaged (Langford et al. 1997). The importance of social engagement and negative impacts of social isolation on health and wellbeing has been well-documented (Nicholson 2012; Thomas 2012; Tomaka, Thompson and Palacios 2006). The structural and functional characteristics of social networks, such as the size of the support system and perceived support, are associated with psychological wellbeing (Gow et al. 2013) and general health and mortality (Berkman and Glass 200o; Cornwell et al. 2009; Rutledge et al. 2004).

The concept of social integration moves beyond social embeddedness and identifies 'active engagement in a variety of social activities' as one of the key relationship factors that impacts wellbeing (Holt-Lunstad and Uchino 2015). Few studies focused on active participation; participating in activities with peers outside the home (House, Robbins and Metzner 1982) and in organised groups (Dalgard and Lund Haheim 1998) were associated with lower mortality, and visiting friends was positively associated with physical functioning and general wellbeing (Menec 2003). In terms of daily activity, sharing meals with others particularly contributes to emotional (Tani et al. 2015) and psychological wellbeing (Van Zandt and Fox 1986), and better nutrition (Grandjean et al. 1981; Hughes, Bennett and Hetherington 2004; Paquet et al. 2008) among older adults. These reports suggest that, among all social relationships that surround older adults, social relationships that involve co-engagement in social or daily activities may be especially beneficial. However, little has been documented about the specific social benefits these relationships provide that other relationships do not. Understanding specific social benefits generated through such relationships can inform future interventions.

Social network interventions aim to enhance social relationships and interactions to facilitate individuals' wellbeing. Interventions to increase social support by introducing new social ties (i.e. volunteers, counsellors) have shown some success, but such approaches do not always yield longterm positive outcomes, potentially due to a lack of empathic understanding, non-reciprocal interactions and the short-term nature of active support provision (Heaney and Israel 2008). 'Enhancing existing network ties' is another way to enhance social networks (Heaney and Israel 2008). Health promotion programmes that involved participants' own social network members showed higher retention and greater health benefits than those that did not include participants' network members (Wing and Jeffery 1999), suggesting the benefits of tapping on to the existing network resources. Given that the societal resources to support and serve 
older adults continue to decrease while the number of older adults increases, strengthening older adults' existing social relationships may represent a viable focus of intervention. For example, existing important relationships can be identified and monitored to maintain positive interactions or intervened upon to trigger new types of interactions that meet the changing needs of older adults over time. With a goal of maximising positive impacts of social relationships, this study aimed to understand older adults' existing social relationships that are especially beneficial to their wellbeing and the functions of these relationships.

Social integration occurs within the context of older adults' social networks, or webs of social ties (Heaney and Israel 2008). The key functions of social networks include social support, social influence and companionship; it is through these functions that health benefits of social relationships are realised (Berkman and Glass 2000; Heaney and Israel 2008). As discussed above, task-oriented social interactions such as engaging in activities or eating together have positive implications on the wellbeing of older adults. To gain a deeper understanding about the social benefits of these types of relationships, we turned to the social network approach and assessed the characteristics of interactions older adults have with each network member. By so doing, this study investigates the extent to which two specific types of interactions, co-engagement in social activity and meal sharing, occur within older adults' social networks; and how these interactions relate to the three key functions of social networks (i.e. social support, companionship, social influence) that have implications on health.

The importance of perceived social support, 'beliefs and perceptions about support availability' (Holt-Lunstad and Uchino 2015), in the health of older adults has been extensively studied and documented (Barth, Schneider and von Kanel 2010; Berkman and Glass 2000; Holt-Lunstad, Smith and Layton 2010; Krause 2001). Types of social support include emotional ('expression of empathy, love, trust, and caring'), instrumental ('tangible aid and services') and informational ('advice, suggestions, and information') (House, Landis and Umberson 1988). Although different types of support often co-occur, each type has unique implications on those receiving support. Whereas emotional support may be important in facilitating psychological wellbeing, older adults experiencing healthrelated challenges may benefit from instrumental and informational support to understand illnesses and services (Heaney and Israel 2008). Older adults do not need support all the time, however, co-engaging in activities with others allows them to maintain relationships that can be activated to provide support when needed (Langford et al. 1997), and participation in social activities has been associated with greater perceived support availability (Fitzpatrick et al. 2005). 
Participating in activities with others also facilitates a sense of companionship. Companionship may not necessarily encompass the exchange of social support, but having someone to participate in activities or eat with can facilitate a sense of belonging and psychological wellbeing (Rook 1987). Conceptual distinction between social support and companionship has been documented with companionship having relatively stronger implications on older adults' psychological wellbeing (Ashida and Heaney 2008 $a$; Rook 1987) and motivation to participate in activities at a senior centre (Ashida and Heaney 20o8b) than social support. The primary reason listed for participation in senior centre activities (Hanssen et al. 1978) and meal services (Dolansky, Moore and Visovsky 2006) was socialisation with other participants. Studies of social relationships have heavily focused on social support (Berkman and Glass 200o), however, investigating the role of companionship along with support can deepen our understanding about social benefits that arise from co-engagement in activities.

Through engaging in activities with others, older adults may also experience social influence, another form of social network function that may have implications on their wellbeing (Berkman and Glass 2000). Receiving encouragement from network members, a direct form of social influence in which network members are intentionally trying to motivate individuals (Lewis and Rook 1999), was associated with higher motivation to engage in health screenings (Ashida, Wilkinson and Koehly 2010) and exercise (Bohm et al. 2016), and to consume a healthy diet (Ashida, Wilkinson and Koehly 2012; Thrasher, Campbell and Oates 2004). It has been suggested that social influence may exert a longer-term impact on individuals' health-promoting behaviours than social support alone (Lewis et al. 20o6). Evaluating the extent to which social influence occurs in relationships that are important to older adults will inform future interventions in developing strategies to facilitate desirable behavioural change.

Although the health benefits of active participation in activities with others have been documented, the pathways through which it leads to wellbeing have not been systematically investigated. With a goal of informing future interventions to increase positive impacts of social relationships, this study investigated whether social network functions (i.e. social support, companionship, social influence) are more likely to occur in relationships that involve active social interactions through co-engagement in activities compared to relationships that do not. Such an understanding will inform whether and how these relationships may be targeted in interventions to enhance social networks. If these relationships bring more benefits than others, interventions may focus on identifying them to assure continued positive functions or on building such relationships. To explore the health implications of network functions considered in this 
study, we further evaluated the associations between the network functions and older adults' sense of wellbeing within our sample.

\section{Methods}

\section{Procedures}

English-speaking adults aged 6o years or older living in a rural Midwestern city in the United States of America (USA) participated in a one-time interview that lasted $45^{-60}$ minutes. Initial respondents (index respondents) were recruited in collaboration with local organisations serving older adults (e.g. ageing service providers, non-profit organisations, churches, housing authority, retiree associations). Respondents identified their personal social network members (e.g. family, friends, service providers) and social interactions they have with them. Their social network members for whom respondents provided permission and contact information were contacted and invited to participate in the study. The analyses presented here include data provided by both index and referred in respondents who were aged 6o years and older living within the city $(\mathrm{N}=133)$. Respondents did not have cognitive or physical limitations that precluded participation in interviews. All respondents provided oral consent before the interview, and received US \$25 after completing an interview. This study was approved by the University of Iowa Institutional Review Board.

\section{Measures}

Social network. Index respondents identified their network members by answering three questions: question 1: '[P]lease list your close family members including your spouse, parents, siblings, children, and grandchildren'; question 2: 'Next, please list anybody else who lives or have lived in your household during the past 12 months'; question 3: 'Now, please list other people who played a role in your life, either positive or negative, during the past 12 months. This can include your friends, neighbors, coworkers, or people you know through groups in your community such as churches and senior centers, and service providers'. Network member respondents enumerated their own network members by first listing the index who referred them into the study, followed by their mutual social ties (friends, family that they both know), and their own family and friends using the questions above.

The number of network members enumerated yielded network size for each respondent. Using the information provided by the respondents, network member characteristics were coded to indicate female, family 
members (as opposed to friend, neighbour, service providers, others), and 60 years and older. Frequency of interaction was measured by asking: 'How often do you see him/her in person; talk to him/her over telephone; come in contact with him/her over internet?' An indicator variable for respondent interacting with the member at least once a month was created for each type of interaction.

Social interactions: co-engagement in activities. Respondents were asked two questions: 'With whom do you engage in social or recreational activities?' and 'With whom do you often share meals?' Network members selected were coded as ' 1 ' as opposed to not selected ('o').

Social network functions. Three of the four types of social support identified by House, Landis and Umberson (1988) were assessed in this study. Respondents identified network members who fit the following descriptions: 'Who provides you with emotional support? (emotional support)/tangible support like giving you a ride and helping with shopping? (instrumental support)/information related to health? (informational support).' Rook described companionship as conceptually distinct from social support (Rook 1987). The concept of companionship highlights the role of social relationships in facilitating the sense of belonging and wellbeing even when relationships do not involve support exchanges. Companionship was more strongly associated with psychological wellbeing of older adults than the three types of social support discussed above (Newsom et al. 2005). In this current study, a question was adopted from the Companionship scale of the Positive and Negative Social Exchanges tool (Newsom et al. 2005) to create a relational measure. Using this relational measure, respondents identified network members 'Who provide [d] [them] with good company and companionship' (companionship) from a list of all network members. Social influence is also identified as one of the key functions of social networks (Berkman and Glass 2000). The relational questions to identify social influence processes were adopted from previous studies that showed the role of social influence on motivation to engage in healthy behaviours among adults aged 18 years and older (Ashida, Wilkinson and Koehly 2012; Ersig et al. 2009). The questions in this current study asked 'Who has encouraged you to get regular health checkups/flu shot/regular physical activity/eat more fruits and vegetables' (social influence: four items). Network members selected were given a code of ' 1 ' and those not selected received ' $O$ ' for each function. Two social influence variables were created to indicate whether the network member provided encouragement to receive health checkups or flu shots (social influence - health care) and encouragement to exercise or eat healthily 
(social influence-behaviour). These values were also aggregated at the respondent level to indicate the number of members each respondent identified for each type of resource.

Psychological responses. Two sub-scales of the Ryff's psychological wellbeing inventory were used to assess older adults' sense of mastery and competence in managing social environment (environmental mastery) and social relationships with others (positive relations with others: seven items each) (Ryff 1989). Ryff's measure emphasises a broad understanding of psychological wellbeing of older adults. Environmental mastery was shown to be associated with lower mood disturbances among individuals with arthritis (Mangelli et al. 2002) and positive relations with others was associated with lower inflammatory response levels among a national sample of middle-aged adults, suggesting health benefits (Friedman and Ryff 2012). Sample questions include 'In general, I feel I am in charge of the situation in which I live' (environmental mastery) and 'I know that I can trust my friends and they know they can trust me' (positive relations with others). Internal validity of these scales have been reported (Ryff 1989; van Dierendonck 2004; Van Dierendonck et al. 2008). An additional question, 'Overall, how satisfied are you with the kinds of relationships you have with people in your social network?' (five-point scale: from 'not at all satisfied' to 'extremely satisfied') was asked to assess overall satisfaction with one's social network.

Respondent characteristics. Based on respondent self-report, indicators for female, white, married (as opposed to not married), high school education or higher, and living alone were created.

\section{Analyses}

Characteristics of the respondents, network members and social relationships were evaluated using descriptive statistics. The first set of analyses assessed whether network functions (social support, companionship, social influence) were more likely to occur within the relationships that involved co-engagement in activities than those that do not at the dyadic level $\left(\mathrm{N}=1,5^{\mathrm{O} 6}\right)$. These analyses included dyads for which respondents indicated that interactions occurred at least once a month; this allowed us to account for variances in interaction frequencies that likely impact their ability to engage in activities together. Generalised linear mixed models using a logistic link function on the probability of a network member exerting a specific network function were used, incorporating a random intercept to account for the dependencies in the data induced by the multiple observations (network members) for each respondent. Some of the 
respondents were either directly connected (i.e. they named each other) or indirectly connected by naming a common network member; thus, a random intercept to account for the dependence induced by this broader network effect was also included. These analyses controlled for network members being family members of, as well as the same gender as, the respondent.

The second set of analyses tested the associations between cognitive outcomes (i.e. environmental mastery, positive relationships with others, satisfaction with social networks) and the functional characteristics of the social networks at the respondent level $(\mathrm{N}=133)$. Linear regression models were used for environmental mastery and the positive relationships, and a proportional odds logistic regression model was used for satisfaction. The models were adjusted by accounting for the following covariates: network size, age, female, white, married (as opposed to not married), high school education or higher, and living alone.

\section{Results}

The characteristics of the respondents and their perceived social relationships are presented in Table 1. Similar to the demographic composition of the study region, the majority of the respondents were white $(86 \%)$ and female $(67 \%)$. The average age was about 75 years, ranging from 61 to 93 , and almost half were married $(45 \%)$. About 9 and 14 per cent of the respondents identified no one in their networks with whom they coengaged in social activities or share meals, respectively. In terms of the psychological states, the average scores were 35.5 for environmental mastery and 36.7 for positive relations with others, both ranging from 20 to 42 . On average, respondents listed 11 social network members, ranging from 1 to 29. The average numbers of network members identified to provide social resources were five for emotional support, six for companionship, two for encouragement to engage in healthy behaviours, and between one and two for instrumental and informational support. The wide ranges for these measures indicate that some respondents identified many members providing these resources whereas others identified no one. The average satisfaction with social network was 3 ('somewhat satisfied'), ranging from 1 to 4 .

A total of 133 respondents reported their personal network environment (egocentric network) using the enumeration questions described above. These respondents altogether identified 1,740 social relationships. Of those, 234 were excluded from the analyses due to the low frequency of interaction (less than once a month through in-person, phone or internet). 
T A B LE 1. Characteristics of the respondents and their social relationships

\begin{tabular}{|c|c|c|c|}
\hline & $\mathrm{N}$ & Mean (SD) or $\%$ & Range \\
\hline \multicolumn{4}{|l|}{ Respondent characteristics: } \\
\hline Age & $13^{1}$ & $75 \cdot 4\left(7 \cdot 4^{8}\right)$ & $61-93$ \\
\hline White & 133 & $85 \cdot 7$ & \\
\hline Female & 133 & 66.5 & \\
\hline Married & 131 & $45 \cdot 0$ & \\
\hline No one to co-engage with: social activities & 133 & $9 \cdot 0$ & \\
\hline No one to co-engage with: eat meals & 133 & 13.5 & \\
\hline Environmental mastery & 100 & $35.5(5.75)$ & $20-42$ \\
\hline Positive relations with others & 129 & $36.7(4.73)$ & $20-4^{2}$ \\
\hline Satisfaction with social network & 133 & $3.2(0.65)$ & $1-4$ \\
\hline \multicolumn{4}{|l|}{ Characteristics of the social relationships: } \\
\hline Social network size & 133 & $11.3\left(5.5^{2}\right)$ & $1-29$ \\
\hline Emotional support & 133 & $4.5(4.73)$ & $0-28$ \\
\hline Instrumental support & 133 & $1.5(1.62)$ & $0-11$ \\
\hline Informational support: health information & 133 & $1.6(1.86)$ & $0-10$ \\
\hline Informational support: community resources & 133 & $1.3(1.92)$ & $0-11$ \\
\hline Companionship & 133 & $6.3(6.03)$ & $0-28$ \\
\hline Social influence: health care & 133 & $1.7(2.29)$ & $0-15$ \\
\hline Social influence: health behaviour & 133 & $2.1(3.24)$ & $0-19$ \\
\hline
\end{tabular}

Notes: $\mathrm{N}=133$. SD: standard deviation. Characteristics of relationships presented as average numbers of network members that respondents indicated as providing the relevant type of resources.

Out of the 1,506 relationships included in the analyses, 1,326 were unique individuals identified in the study. Some of these egocentric networks became connected when respondents identified common social network members, thus, we had a total of $4^{6}$ groups of networks in which one or more egocentric network existed ( 46 disconnected components to the egocentric network). Figure 1 presents one of the disconnected components that includes 13 egocentric networks, showing social interactions (dashed line indicates co-engagement in either social activities or eating, solid line indicates no co-engagement) as reported by the respondents (black circle). Out of 8,778 possible pairs between the 133 respondents $(133 \times$ $132 / 2), 8,426$ were disconnected within our egocentric network data.

Table 2 presents the characteristics of social network members and social relationships. These characteristics are presented separately for the relationships that involved and did not involve co-engagement. The average age of the network members was about 6o years; about 6o per cent of them were the same gender as the respondent. Respondents identified an average of 5.9 and 4.0 network members as someone with whom they engage in social activities and eat meals, respectively. Simple bivariate analyses ( $t$-test for age, $Z$-test for all other variables) showed that higher proportions of members who co-engage in social activities with the respondent as 


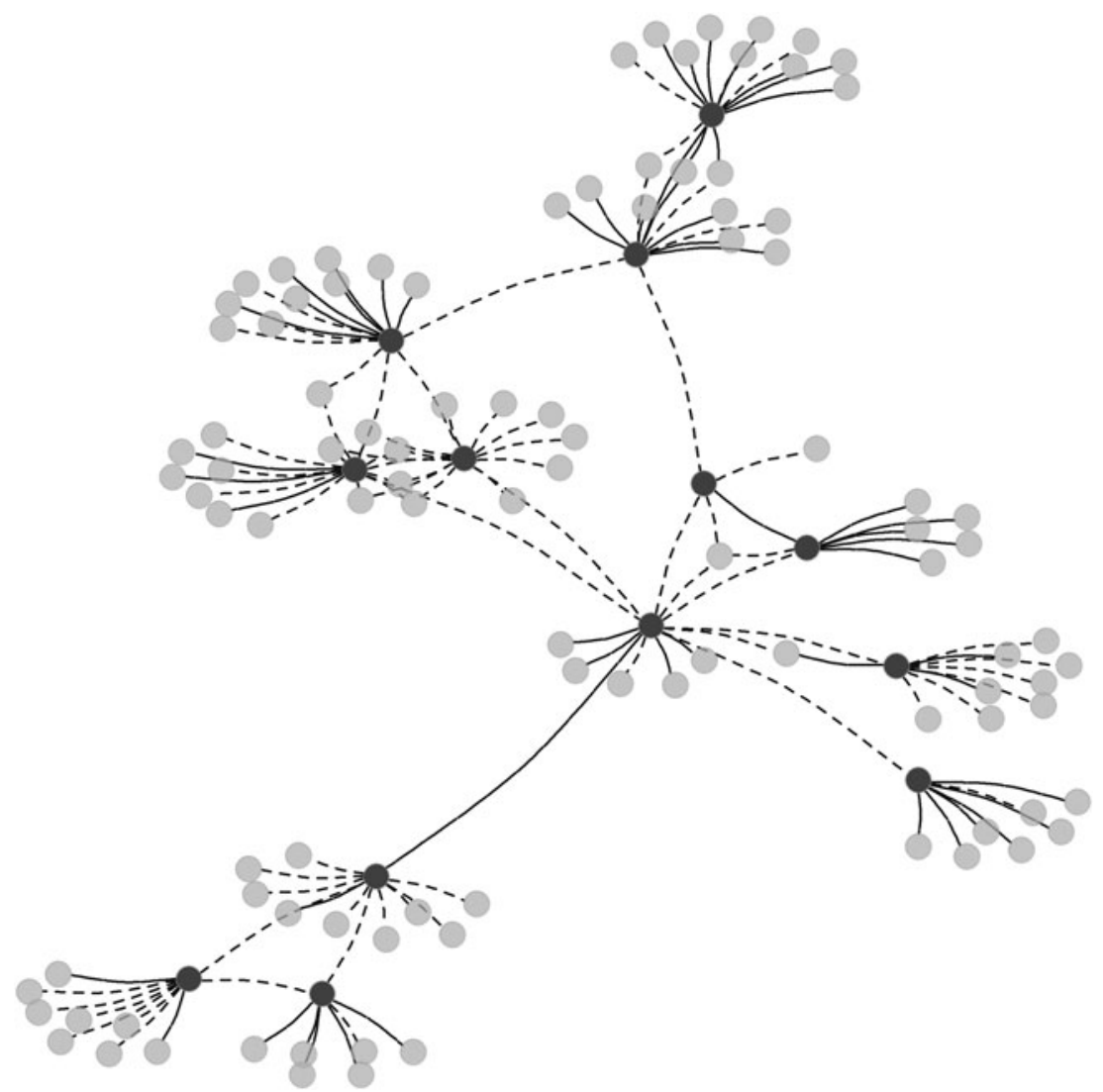

Figure 1. A group of connected egocentric social networks based on the information provided by 13 respondents.

Note. Dark circles indicate respondents/egos, grey circles indicate network members/alters, dashed lines indicate co-engagement in either social activities or eating meals, and solid lines indicate no co-engagement.

opposed to do not co-engage live within the community (8o\% versus $69 \%$ ) and live with the respondents $(6 \%$ versus $3 \%)$. For eating together, higher proportions of the members who co-engage as compared to do not coengage lived within the community $(89 \%$ versus $67 \%)$ and lived with the respondents $(10 \%$ versus $2 \%)$. About 36 per cent of the non-spousal members with whom respondents eat were identified as family members as opposed to non-family, indicating that a large proportion of members with whom respondents share meals are non-family members.

As reported in Table 3, respondents reported significantly higher likelihood of receiving all types of social resources (i.e. emotional, instrumental, informational, companionship, social influence) within the relationships 
T A B LE 2. Characteristics of the social network members and relationships

\begin{tabular}{|c|c|c|c|}
\hline & $\begin{array}{l}\text { Engage } \\
\text { together }\end{array}$ & $\begin{array}{l}\text { Do not engage } \\
\text { together }\end{array}$ & $p\left(\mathrm{CI}^{1}\right)$ \\
\hline \multicolumn{4}{|l|}{ Social activities: } \\
\hline $\mathrm{N}(\%)$ & $785\left(5^{2.1}\right)$ & $721(47.9)$ & \\
\hline Mean age (SD) & $59 \cdot 4(21.3)$ & $59.9(53.4)$ & $0.85(-4.6,3.8)$ \\
\hline Same gender as respondent $(\%)$ & 62.5 & 60.5 & $0.44(-3.0,7.1)$ \\
\hline Family member $(\%)^{2}$ & $4^{1.4}$ & $5^{1.8}$ & $<0.001(-15.6,-5.1)$ \\
\hline Live within the community (\%) & $79 \cdot 5$ & $69 \cdot 3$ & $<0.001(5.6,14.7)$ \\
\hline Live with respondent (\%) & 5.86 & 2.8 & $0.005(0.9,5 \cdot 3)$ \\
\hline \multicolumn{4}{|l|}{ Eat meals: } \\
\hline $\mathrm{N}(\%)$ & $533(35 \cdot 4)$ & $973(64.6)$ & \\
\hline Mean age (SD) & $61.9(21.7)$ & $58.4(47.0)$ & $0.05(-0.05,6.92)$ \\
\hline Same gender as respondent $(\%)$ & $5^{8.2}$ & 63.4 & $0.05(-10.6,0.06)$ \\
\hline Family member $(\%)^{2}$ & $35 \cdot 7$ & $5^{1.9}$ & $<0.001(-21.6,-10.7)$ \\
\hline Live within the community (\%) & 88.6 & 67.0 & $<0.001(17.4,25.7)$ \\
\hline Live with respondent (\%) & 9.6 & 1.5 & $<0.001(5.3,10.8)$ \\
\hline
\end{tabular}

Notes: $\mathrm{N}=1,5 \mathrm{o6}$. SD: standard deviation. 1. Confidence interval for the difference between 'Engage together' and 'Do not engage together'. 2. Calculated with spouses excluded.

that involved co-engagement in social activities or eating compared to the relationships that do not involve the relevant interactions. Respondents were almost ten times more likely to perceive a sense of companionship, and three times more likely to perceive receiving emotional support as well as encouragement to engage in healthy behaviours within relationships that involve co-engagement in social activities than the relationships that do not (all $p<0.001)$. These analyses controlled for network members being family, same gender as respondent, living within the same community and living with the respondent. Similarly, respondents were three times more likely to perceive a sense of companionship, and two times more likely to receive emotional support, instrumental support and information about community resources from members with whom they share meals compared to other members.

The results of the linear regression models showed that a higher number of network members identified as providing companionship was associated with higher scores of environmental mastery $(\beta=0.26, p=0.05)$ and positive relations $(\beta=0.20, p=0.04)$. Similarly, a proportional odds logistic regression model indicated that overall satisfaction with network $(\beta=0.14, p<$ o.01) was also associated with the number of members who provided companionship to the respondents. These analyses controlled for the network size, as well as race, marital status, living status and gender of the respondents. The number of members who provided various types of social support and social influence was not associated with the outcomes. 
TA в L E 3. Associations between functional characteristics of social networks and engagement in activities together

\begin{tabular}{|c|c|c|c|c|c|c|c|}
\hline & $\begin{array}{l}\text { Emotional } \\
\text { support }\end{array}$ & $\begin{array}{l}\text { Instrumental } \\
\text { support }\end{array}$ & $\begin{array}{c}\text { Informational: } \\
\text { health }\end{array}$ & $\begin{array}{l}\text { Informational: } \\
\text { resource }\end{array}$ & Companionship & $\begin{array}{l}\text { Social influence: } \\
\text { health care }\end{array}$ & $\begin{array}{c}\text { Social influence: } \\
\text { behaviour }\end{array}$ \\
\hline \multicolumn{8}{|c|}{ Social activities together: } \\
\hline OR & 3.02 & 1.92 & 2.55 & 2.87 & 9.80 & 1.73 & $3 \cdot 43$ \\
\hline$\beta(\mathrm{SE})$ & $1.1(0.20)$ & $0.7(0.26)$ & $0.9(0.22)$ & $1.1(0.29)$ & $2.3(0.26)$ & $0.6(0.28)$ & $1.2(0.28)$ \\
\hline$p$ & $<0.001$ & 0.01 & $<0.001$ & $<0.001$ & $<0.001$ & 0.05 & $<0.001$ \\
\hline \multicolumn{8}{|l|}{ Eat with: } \\
\hline OR & 2.20 & 2.83 & 1.48 & 2.21 & $3 \cdot 37$ & 1.71 & $2.5^{2}$ \\
\hline$\beta(\mathrm{SE})$ & $0.8(0.19)$ & $1.0(0.23)$ & $0.4(0.21)$ & $0.8(0.28)$ & $1.2(0.25)$ & $0.5(0.27)$ & $0.9(0.26)$ \\
\hline$p$ & $<0.001$ & $<0.001$ & 0.06 & 0.005 & $<0.001$ & 0.04 & $<0.001$ \\
\hline
\end{tabular}

Notes: OR: odds ratio. SE: standard error (SE indicates Standard Error). Models control for network member being family (versus non-family), same gender as ego, in same community as ego and co-habitating status; comparison group is network members with whom respondents interacted at least once a month but did not co-engage in the relevant activity. 


\section{Discussion}

This research used a social network approach to deepen our understanding of the social benefits older adults receive from engaging in social and daily activities with others. To gain a broader view of older adults' social contexts, we assessed their networks that included their family and relatives as well as community-based non-family social ties. About half of the network members listed by our study respondents were identified as someone with whom they engage in social activities, and a little over one-third were identified as someone with whom they share meals. Results highlight the beneficial nature of social relationships that involve co-engagement in social and daily activities; all types of social resources investigated, including social support, companionship and social influence (encouragement to engage in healthy behaviours), were more likely to occur within social relationships in which older adults and network members engaged in social activities or ate meals together compared to the relationships in which they did not. These associations remained over and above network member characteristics such as gender, and relationship (family members versus non-family) and geographic proximity to the respondent. The further analyses showed that having more network members who provide companionship was associated with a higher sense of mastery and competence in managing one's own environment, satisfying and trusting relationships with others, and satisfaction with own social network.

Although the benefits of relationships involving co-engagement in activities included all three types of functions (i.e. social support, companionship, social influence), companionship appears to be the prime social benefit reported by the respondents. Relationships involving co-engagement were ten times more likely to bring companionship than other relationships. Companionship was also over three times more likely to occur in relationships involving meal sharing than those that do not. Our result showing the significant association between the number of network members who provide companionship and the psychological states of the respondents (i.e. environmental mastery, positive relationships, satisfaction with networks), along with the previous literature showing the relative importance of companionship compared to social support (Ashida and Heaney 2008a; Rook 1987), highlights the importance of actively considering companionship as a key component to intervene upon in social network interventions. Whereas social support often represents one-way interaction (receipt of support), companionship likely facilitates a mutual exchange of social resources, which enhances a sense of reciprocity that older adults value (Silverstein, Chen and Heller 1996). Altogether, our findings show that facilitating co-engagement in activities, rather than provision of 
support as many previous interventions have done, may be effective in enhancing a sense of companionship and social connectedness among older adults, thus reducing perceived loneliness. Future studies may longitudinally investigate whether facilitating co-engagement in activities leads to a higher sense of companionship, lower perceived loneliness and better psychological wellbeing.

The numbers of network members providing social support or encouragement to engage in healthy behaviours were not associated with the psychological measures considered in this study. This finding may be partly due to the small sample size used for the respondent-level analyses. It has been shown that, in the face of physical decline, older adults receive increasing amounts of instrumental support from their network members (Broese van Groenou and Van Tilburg 1997), thus, the need for such support may mask the positive association between social support and wellbeing. For social influence, it may be that the encouragement to engage in healthy behaviours has more direct implications on respondents' health-related behaviours, as shown in previous research (Ashida, Wilkinson and Koehly 2010; Bohm et al. 2016), rather than on psychological wellbeing. While some older adults may perceive such encouragement as supportive, others may perceive it as intrusive or unwanted, potentially cancelling out its association with psychological wellbeing. Future studies may investigate whether such presence of social influence or encouragement have implications for older adults' health behaviours or motivation to engage in such behaviours. Nonetheless, our findings support the relevance of companionship as a key factor that should be considered in public health efforts to facilitate the psychological wellbeing of older adults.

Although our study did not show that psychological outcomes were associated with social support and influence, these types of resources have previously been shown to facilitate health and wellbeing (Berkman and Glass 200o). These resources that can be potentially activated within social networks, also referred to as social capital, were highlighted as key factors that can support individuals to age well (Keating, Swindle and Foster 2005). The findings of this current study add to the understanding of social capital within older adults' social networks, and shed light on specific actions (i.e. facilitate co-engagement) that can be used to exert positive impacts of networks. The concept of companionship has not been wellexplored in the current literature (Newsom et al. 2005). However, our findings suggest that a greater sense of companionship may be the key function through which social capital can enhance the psychological wellbeing of older adults. Further studies evaluating how companionship may mediate the associations between co-engagement and health outcomes will be beneficial. 
A majority of the network members whom respondents identified as engaging in activities together were more likely to live within the local area and to be non-family members (e.g. friends, neighbours and individuals from community-based agencies) than family. These findings suggest the importance of social network members who live within the same community who are not family members of the older adults. Historically, research on social contexts of older adults focused on family support systems. However, the relative importance of friends compared to family for older adults is increasingly being documented (Adams and Blieszner 1995; DuPertuis, Aldwin and Bossé 2001; Fiori, Antonucci and Cortina 2006; Golden, Conroy and Lawlor 2009; Litwin 2001, 2011). Our findings highlight the benefits of considering local, non-family social ties of community-residing older adults as targets of interventions to maintain and facilitate positive social interactions. As geographic distances among family members continue to increase (Fischer and Hout 2006) and concerns about social isolation among older adults increase, especially in rural areas, these nonfamily local ties become even more valuable and should be actively considered in interventions to support the maintenance of these relationships. Anecdotally, communities in the USA are experiencing closures of senior and community centres with diminishing resources. Continuing to provide the settings and situations in which older adults and their locally based network members can co-engage in activities is of prime importance.

Although 9 per cent of the respondents in this current study did not list anyone with whom they either engage in social activities or eat meals, all respondents belonged to social networks, some of which were rather large. Thus, social ties that currently do not involve co-engagement in activities can be identified and mobilised within their existing networks. Given the importance of local network members, those who live within the local area can be sought out to facilitate active social interactions. Approaches used in this study to assess social networks can be used to identify potential members that can be reached. Concerns exist about older adults who may not have any social ties with whom they can engage in social activities or eat meals. In the state of Iowa, where this study took place, 45 percent of those aged 65 years and older live alone (Iowa Department on Aging 2015), and thus are at risk of social isolation. In such cases, using a different social network intervention approach such as 'developing new social network linkages' becomes necessary (Heaney and Israel 2008). Research shows the importance of new social ties having similar experiences or values as the focal individual (Eckenrode and Hamilton 2000), and focusing on naturally occurring social relationships may be beneficial (Berkman 1995).

This study was conducted in a rural community in the Midwestern USA, thus, findings cannot be generalised to older residents in other 
communities that may have different historical and cultural backgrounds or experience different physical and social environments. All data were collected at the same time, limiting our ability to determine causal associations. All responses were self-reported and may be subjected to recall and social desirability biases. Because the main variable of interest, co-engagement, required interactions, we limited our analyses to social ties that involved a minimum interaction frequency of once a month. Thus, differences in interaction frequencies by different types of resources was not investigated. Although potential dependency among the respondents who belong to the same social networks were accounted for in the analyses, unique characteristics of social interactions or environments that may exist in some networks were not considered in the analyses as most networks only had one or two respondents who participated in interviews, limiting our ability to pool their information to characterise such social environmental characteristics. Although this was a pilot study, the findings provide insight into the social benefits older adults gain from co-engaging in social and daily activities with others and specific benefits that may have implications for facilitating their psychological wellbeing.

\section{Implications}

This study confirms the importance of older adults engaging in social and daily activities with others to access valuable social resources such as social support, companionship and encouragement to engage in healthy behaviours. The findings of this study point to three potential areas of focus in future interventions: (a) supporting older adults to maintain existing social relationships that involve co-engagement in activities, (b) activating social interactions to involve co-engagement among existing relationships that currently do not involve co-engagement, and (c) identifying and adding new social network members who co-engage in activities with older adults.

In the face of declining social resources and services, it is important that our societies continue to provide social settings in which older adults and their network members can engage in activities together (e.g. community centres, meal programmes). Our results showed that a large proportion of older adults' existing network members did not co-engage in these activities with the respondents, revealing untapped resources within the immediate surroundings of these individuals. These inactive social relationships are described as network social capital that can be mobilised to provide resources (Tijhuis et al. 1998). Interventions may focus on activating these relationships by informing network members about the importance of co-engagement or providing older adults with information and skill to help mobilise these 
social ties. Older adults with small and limited social networks would benefit from developing new relationships. Our results suggest that non-family, locally based social ties may be especially suitable for developing new, active relationships. The social network assessment approach used in this study that moves beyond families to capture broader networks can be used to identify network members who can be recruited to develop such relationships. Future research may evaluate whether facilitating co-engagement leads to an enhanced sense of companionship that, in turn, may lead to a reduction in loneliness and improved psychological wellbeing among older adults.

\section{Acknowledgements}

We would like to thank the participants of this study for sharing their stories, thoughts and expertise. This study was supported by Cooperative Agreement Number 1-U48DPoo19o2-o1 from the Centers for Disease Control and Prevention in the USA. The findings and conclusions in this report are those of the authors and do not necessarily represent the official position of the Centers for Disease Control and Prevention. This research followed the procedures that were approved by the Institutional Review Board of The University of Iowa. S. Ashida conceptualised and designed the study, collected and analysed data, and wrote the paper. D. Sewell helped to conceptualise the paper, design the analytical approach, analyse data, and draft and revise the paper. E. Schafer helped to collect and manage data, analyse data, and draft and revise the paper. A. Schroer and J. Friberg helped to collect data and draft the paper, and provided critical feedback. All authors approved the submission of this paper. The authors declare no conflicts of interest.

\section{References}

Adams, R. G. and Blieszner, R. 1995. Aging well with friends and family. The American Behavioral Scientist, 39, 2, 209-24.

Ashida, S. and Heaney, C. A. 2008a. Differential associations of social support and social connectedness with structural features of social networks and the health status of older adults. Journal of Aging and Health, 2o, 7, 872-93.

Ashida, S. and Heaney, C. A. 2008b. Social networks and participation in social activities at a new senior center: reaching out to older adults who could benefit the most. Activities, Adaptation $\mathcal{E}^{\circ}$ Aging, 32, 1, 40-55.

Ashida, S., Wilkinson, A. V. and Koehly, L. M. 2010. Motivation for health screening: evaluation of social influence among Mexican-American adults. American Journal of Preventive Medicine, 38, 4, 396-402.

Ashida, S., Wilkinson, A. V. and Koehly, L. M. 2012. Social influence and motivation to change health behaviors among Mexican-origin adults: implications for diet and physical activity. American Journal of Health Promotion, 26, 3, 1 76-9.

Barth, J., Schneider, S. and von Kanel, R. 2010. Lack of social support in the etiology and the prognosis of coronary heart disease: a systematic review and meta-analysis. Psychosomatic Medicine, 72, 3, 229-38. 
Berkman, L. F. 1995. The role of social relations in health promotion. Psychosomatic Medicine, 57, 3, 245-54.

Berkman, L.F. and Glass, T.A. 200o. Social integration, social networks, social support, and health. In Berkman, L. F. and Kawachi, I. (eds), Social Epidemiology. Oxford University Press, New York, 137-73.

Bohm, A. W., Mielke, G. I., da Cruz, M. F., Ramirez, V. V. and Wehrmesister, F. C. 2016. Social support and leisure-time physical activity among the elderly: a population-based study. Journal of Physical Activity and Health, 13, 6, 599-605.

Broese van Groenou, M. and Van Tilburg, T. 1997. Changes in the support networks of older adults in the Netherlands. Journal of Cross-cultural Gerontology, 1 2, 1, 23-44.

Cornwell, B., Schumm, L. P., Laumann, E. O. and Graber, J. 20og. Social networks in the NSHAP study: rationale, measurement, and preliminary findings. Journals of Gerontology: Psychological Sciences and Social Sciences, 64B, supplement 1, 147-55.

Dalgard, O. S. and Lund Haheim, L. 1998. Psychosocial risk factors and mortality: a prospective study with special focus on social support, social participation, and locus of control in Norway. Journal of Epidemiology and Community Health, 52, 8, 476-81.

Dolansky, M. A., Moore, S. M. and Visovsky, C. 20o6. Older adults' views of cardiac rehabilitation program: is it time to reinvent? Journal of Gerontological Nursing, 32, 2, 37-44.

DuPertuis, L. L., Aldwin, C. M. and Bossé, R. 2001. Does the source of support matter for different health outcomes? Findings from the Normative Aging Study. Journal of Aging and Health, 13, 4, 494-510.

Eckenrode, J. and Hamilton, S. 2ooo. One-to-one support interventions: home visitation and mentoring. In Cohen, S., Underwood, L. G. and Gottlieb, B. H. (eds), Social Support Measurement and Intervention. Oxford University Press, New York, $246-77$.

Ersig, A. L., Williams, J. K., Hadley, D. W. and Koehly, L. M. 20og. Communication, encouragement, and cancer screening in families with and without mutations for hereditary nonpolyposis colorectal cancer: a pilot study. Genetics in Medicine, $11,10,728-34$.

Fiori, K. L., Antonucci, T. C. and Cortina, K. S. 20o6. Social network typologies and mental health among older adults. Journals of Gerontology: Psychological Sciences and Social Sciences, 61B , 1, 25-32.

Fischer, C. S. and Hout, M. 20o6. Century of Difference: How America Changed in the Last One Hundered Years. Russell Sage, New York.

Fitzpatrick, T. R., Gitelson, R.J., Andereck, K. L. and Mesbur, E. S. 2005. Social support factors and health among a senior center population in southern Ontario, Canada. Social Work in Health Care, 4o, 3, $15^{-37}$.

Friedman, E. M. and Ryff, C. D. 2012 . Living well with medical comorbidities: a biopsychosocial perspective. Journals of Gerontology: Psychological Sciences and Social Sciences, 67 B, $5,535^{-44}$.

Golden, J., Conroy, R. M. and Lawlor, B. A. 2009. Social support network structure in older people: underlying dimensions and association with psychological and physical health. Psychology, Health Eॄ Medicine, 14, 3, 280-9o.

Gow, A.J., Corley, J., Starr, J. M. and Deary, I.J. 2013. Which social network or support factors are associated with cognitive abilities in old age? Gerontology, 59, $5,454^{-63}$.

Grandjean, A. C., Korth, L. L., Kara, G. C., Smith, J. L. and Schaefer, A. E. 1981. Nutritional status of elderly participants in a congregate meals program. Journal of the American Dietetic Association, 78, 4, 324-9.

Hanssen, A. M., Meima, N.J., Buckspan, L. M., Henderson, B. E., Helbig, T. L. and Zarit, S. H. 1978. Correlates of senior center participation. The Gerontologist, 18, 2, 193-200. 
Heaney, C. A. and Israel, B. A. 2008. Social networks and social support. In Glanz, D. K., Rimer, B. K. and Viswanath, K. (eds), Health Behavior and Health Education: Theory, Research, and Practice. Jossey-Bass, San Francisco, 189-2 10.

Holt-Lunstad, J., Smith, T. B. and Layton, J. B. 2010. Social relationships and mortality risk: a meta-analytic review. PLoS Medicine, 7, 7, e 1000316.

Holt-Lunstad, J. and Uchino, B. N. 2015. Social support and health. In Glanz, K., Rimer, B. K. and Viswanath, K. (eds), Health Behavior: Theory, Research, and Practice. John Wiley \& Sons, San Francisco, 183-204.

House, J. S., Landis, K. R. and Umberson, D. 1988. Social relationships and health. Science, 241, $4865,54^{-}-5$.

House, J. S., Robbins, C. and Metzner, H. L. 1982. The association of social relationships and activities with mortality: prospective evidence from the Tecumseh Community Health Study. American Journal of Epidemiology, 1 16, 1, 123-40.

Hughes, G., Bennett, K. M. and Hetherington, M. M. 2004. Old and alone: barriers to healthy eating in older men living on their own. Appetite, 43, 3, 269-76.

Iowa Department on Aging 2015. Older Iowans: 2015. Iowa Department on Aging, Des Moines, Iowa.

Keating, N., Swindle, J. and Foster, D. 2005. The role of social capital in aging well. In Social Capital in Action: Thematic Policy Studies. Policy Research Initiative, Government of Canada, Ottawa, $24^{-} 5^{1 .}$

Krause, N. 2001 . Social support. In Binstock, R. H. and George, L. K. (eds), Handbook of Aging and the Social Sciences. Academic Press, San Diego, California, 272-94.

Langford, C. P., Bowsher, J., Maloney, J. P. and Lillis, P. P. 1997. Social support: a conceptual analysis. Journal of Advanced Nursing, 25, 1, 95-100.

Lewis, M. A., McBride, C. M., Pollak, K. I., Puleo, E., Butterfield, R. M. and Emmons, K. M. 2006. Understanding health behavior change among couples: an interdependence and communal coping approach. Social Science $\mathcal{E} \mathcal{F}^{\mathrm{M}}$ Medicine, 62, 6, 1369-80.

Lewis, M. A. and Rook, K. S. 1999. Social control in personal relationships: impact on health behaviors and psychological distress. Health Psychology, 18, 1, 63-71.

Litwin, H. 2001. Social network type and morale in old age. The Gerontologist, 41, 4, $5^{16-24}$.

Litwin, H. 2011 . The association between social network relationships and depressive symptoms among older Americans: what matters most? International Psychogeriatrics, 23, 6, 930-40.

Mangelli, L., Gribbin, N., Buchi, S., Allard, S. and Sensky, T. 2002. Psychological wellbeing in rheumatoid arthritis: relationship to 'disease' variables and affective disturbance. Psychotherapy and Psychosomatics, 71, 2, 11 2-6.

Menec, V.H. 2003. The relation between everyday activities and successful aging: a 6-year longitudinal study. Journals of Gerontology: Psychological Sciences and Social Sciences, 58B, 2, S74-82.

Newsom, J. T., Rook, K. S., Nishishiba, M., Sorkin, D. H. and Mahan, T. L. 2005. Understanding the relative importance of positive and negative social exchanges: examining specific domains and appraisals. Journals of Gerontology: Psychological Sciences and Social Sciences, 6oB, 6, $\mathrm{P}_{3} \mathrm{O}_{4}-12$.

Nicholson, N. R. 2012. A review of social isolation: an important but underassessed condition in older adults. Journal of Primary Prevention, 33, 2/3, 137-52.

Paquet, C., St-Arnaud-McKenzie, D., Ma, Z., Kergoat, M.-J., Ferland, G. and Dube, L. 2008. More than just not being alone: the number, nature, and complementarity of meal-time social interactions influence food intake in hospitalized elderly patients. The Gerontologist, 48, 5, 603-11.

Rook, K. S. 1987. Social support versus companionship: effects on life stress, loneliness, and evaluations by others. Journal of Personality and Social Psychology, 52, 6, $1132-47$. 
Rutledge, T., Reis, S. E., Olson, M., Owens, J., Kelsey, S. F., Pepine, C. J., Mankad, S., Rogers, W.J., Bairey Merz, C. N., Sopko, G., Cornell, C. E., Sharaf, B. and Matthews, K. A. 2004. Social networks are associated with lower mortality rates among women with suspected coronary disease: the National Heart, Lung, and Blood Institute-Sponsored Women's Ischemia Syndrome Evaluation study. Psychosomatic Medicine, 66, 6, 882-8.

Ryff, C. D. 1989. Happiness is everything, or is it? Explorations on the meaning of psychological well-being. Journal of Personality $\mathcal{E}^{2}$ Social Psychology, 57, 6, 1069-81.

Silverstein, M., Chen, X. and Heller, K. 1996. Too much of a good thing? Intergenerational social support and the psychological well-being of older parents. Journal of Marriage and the Family, 58, 4, 970-82.

Tani, Y., Sasaki, Y., Haseda, M., Kondo, K. and Kondo, N. 2015. Eating alone and depression in older men and women by cohabitation status: the JAGES longitudinal survey. Age and Ageing, 44, 6, 1019-26.

Thomas, P.A. 2012. Trajectories of social engagement and mortality in late life. Journal of Aging and Health, 24, 4, 547-68.

Thrasher, J. F., Campbell, M. K. and Oates, V. 2004. Behavior-specific social support for healthy behaviors among African American church members: applying optimal matching theory. Health Education and Behavior, 31, 2, 193-205.

Tijhuis, M. A. R., Flap, H. D., Foets, M. and Groenewegen, P. P. 1998. Selection in the social network: effects of chronic diseases. European Journal of Public Health, 8, 4, 286-93.

Tomaka, J., Thompson, S. and Palacios, R. 2006. The relation of social isolation, loneliness, and social support to disease outcomes among the elderly. Journal of Aging and Health, 18, 3, 359-84.

van Dierendonck, D. 2004. The construct validity of Ryff's Scales of Psychological Well-being and its extension with spiritual well-being. Personality and Individual Differences, 36, 3, 629-43.

Van Dierendonck, D., Diaz, D., Rodriguez-Carvajal, R., Blanco, A. and MorenoJimenez, B. 2008. Ryff's six-factor model of psychological well-being: a Spanish exploration. Social Indicators Research, 87, 473-9.

Van Zandt, S. and Fox, H. 1986. Nutritional impact of congregate meals programs. Journal of Nutrition for the Elderly, 5, 3, 31-44.

Wing, R. R. and Jeffery, R. W. 1999. Benefits of recruiting participants with friends and increasing social support for weight loss and maintenance. Journal of Consulting and Clinical Psychology, 67, 1, 132-8.

Accepted I4 November 2017 ; first published online 8 January 2018

Address for correspondence:

Sato Ashida,

Department of Community \& Behavioral Health,

The University of Iowa College of Public Health,

The University of Iowa Aging Mind and Brain Initiative (AMBI),

145 North Riverside Drive,

Iowa City, IA 52242 , USA

E-mail: sato-ashida@uiowa.edu 